\title{
Journal of Bacteriology and

\section{Epidemiology of Tinea Capitis and Associated Factors among School Age Children in Hawassa Zuria District, Southern Ethiopia, 2016}

\section{Desalegn Tsegaw Hibstu* and Deresse Legesse Kebede}

School of Public and Environmental Health, College of Medicine and Health Sciences, Hawassa University, Hawassa, Ethiopia

"Corresponding author: Desalegn Tsegaw Hibstu, School of Public and Environmental Health, College of Medicine and Health Sciences, Hawassa University, Hawassa, Ethiopia, E-mail: desuethiopia@yahoo.com

Received date: April 21, 2017; Accepted date: May 12, 2017; Published date: May 17, 2017

Copyright: (C2017 Hibstu DT. This is an open-access article distributed under the terms of the Creative Commons Attribution License, which permits unrestricted use, distribution, and reproduction in any medium, provided the original author and source are credited.

\begin{abstract}
Introduction: Africa, being the settings mostly affected, the rates of tinea infection ranges between 10 and $30 \%$ among school-aged children. For instance in Ethiopia, the prevalence of tinea capitis among school children was $47.5 \%$. The aim of this study was to determine the magnitude of tinea capitis and associated factors among school age children in Dorebafano town, Hawassa Zuria Disrict, Southern Ethiopia.

Methods: A community based cross-sectional study design was conducted among 292 children in Dorebafano town from June 30 to July 6, 2016 using systematic random sampling technique. Data was collected using pretested and interviewer administered structured questionnaire. The presence or absence of tinea capitis was confirmed by physical examination and taking samples from scalp scratch and observing under a microscope with potassium hydroxide $(\mathrm{KOH})$. Logistic regression was carried out to identify factors associated with presence of tinea capitits. Model fitness was checked using Hosmer and Lemeshow show.
\end{abstract}

Result: The magnitude of tinea capitis among the study subjects was $32.3 \%$ [Cl: $27.3 \%-37.5 \%$ ]. Age of child $(A O R=3.2,95 \% \mathrm{Cl}: 1.40,7.00)$, sex of child $(\mathrm{AOR}=0.10, \mathrm{Cl}(0.03,0.40)$, educational status of the child $(\mathrm{AOR}=6.9$, $95 \% \mathrm{Cl}: 1.4,33.5)$ and presence of similar illness (AOR=6.49, 95\% Cl: $2.42,17.43$ ) were identified to be independent factors for the occurrence of tinea capitis.

Conclusion: The magnitude of tinea capitis among the study subjects was found to be high. Age, sex, educational status of children and presence of similar illness were identified factors for occurrence of tinea capitis. Health promotion, health education measures and early identification and treatment of tinea capitis need to be given emphasis.

Keywords: Tinea capitis; School aged children; Dorebafano town

\section{Introduction}

Tinea capitis is a disease resulted due to cutaneous infection of the scalp, eye lashes and eye brows. Similar terms are used to name the infection, including ringworm of the scalp and Tinea tonsurans. The disease is considered to be a form of superficial mycosis or dermatophytosis [1]. It accounts for up to $92.5 \%$ of dermatophytoses in children younger than 10 years [2,3]. It is a contagious disease which is endemic in many countries that causes specific therapeutic challenges [4].

In spite of the high cases being detected in poor resource settings, these infections have a worldwide distribution with most cases being diagnosed in Africa, Asia, and Southern and Eastern Europe [5-7] and having curable nature of the disease, inter-human transmission of tinea capitis is nevertheless a significant public health problem due to the increasing number of children affected and the risk of contagion in schools [8] where its transmissibility enhanced by poor hygiene, overcrowding, contaminated hats, brushes, pillows and other inanimate objects [9].

Africa, being the settings mostly affected, the rates of tinea infection ranges between 10 and 30\% among school-aged children [10]. For instance in Ethiopia, Nigeria and Palestine, the prevalence of tinea capitis among school children was $47.5 \%, 40 \%$ and $27 \%$ respectively [11-13] yet it is now uncommon in the developed world due to improved social condition and the development of effective treatments [14].

Tinea capitis happens predominantly in rural areas and some of the factors that favor the occurrence of the infections are poor personal hygiene, overcrowding, and low socioeconomic status [15], educational and occupational status of parents, being male, sharing facilities, close contact with people with the diseases as contributing factors. Organisms that cause tinea capitis are usually found as fomites on items such as combs, hats, pillows, and theater seats, where the spores can live for long periods of time, contributing to spread of the disease [16].

Nevertheless, the epidemiological distribution of tinea capitis has shown diverse geographical and seasonal variations depending on several factors, including life style, type of the population, migration of people and climatic conditions [17]. Apart from climate, the variability in distribution of dermatophytes worldwide is attributed to other factors such as population migration patterns, lifestyle, primary host range, secondary host immunity, presence of immunodeficiency diseases, and patient's attitude to prompt treatment following clinical presentation and standard of living $[18,19]$. 
Difficulty of obtaining information from children, anxiety of children about the examinations and hair removal, incorrect information regarding monthly income and personal hygiene, unawareness of peoples who are interviewed about Tinea capitis, nature of study sample and its size, lack of appropriate policy for controlling tinea capitis were some of the obstacles identified in the prevention and control of tinea capitis [20,21].

Health promotion and health education to promote good hygiene, better living conditions, early identification and treatment, periodic surveillance of Tinea capitis, training for school teachers and appropriate policy were some the recommended interventions to control this contagious infection [20,22]. Therefore, this study was aimed to determine the magnitude of tinea capitis and associated factors among school aged children in Dore bafano town, Hawassa Zuria District, Sidama Zone, Southern Ethiopia.

\section{Materials and Methods}

\section{Study setting}

The present study was conducted in Dore Bafano town, Hawassa Zuria District, Sidama Zone, Southern Ethiopia. The town is located 23 kilometer (KM) from Hawassa; capital city of Southern Nation and Nationalities and people Region, Ethiopia and $298 \mathrm{KM}$ far from Addis Ababa; capital city of Ethiopia.

\section{Study design and population}

Community based quantitative cross sectional study design was employed to assess the magnitude of tinea capitis and associated factors among school age children (6-15 years). The source and study population were all school age children with their parents/care takers and living in Dorebafano town. Children who were diagnosed as, mentally and physically not capable of being interviewed, by physicians and residing in the study area for less than six months were excluded from the study.

\section{Sample size and sampling procedure}

Sample size was determined using single population proportion formula considering the following assumption: 95\% confidence level $(\mathrm{Za} / 2), 5 \%$ margin of error (d) and proportion (p) of tinea capitis in previous study was taken as $47.5 \%$ [11].

$$
\left.\mathrm{n} \text { (sample size) }=Z_{\alpha / 2}\right)^{2} \frac{P[1-P]}{d^{2}}, \mathrm{n}=383 \text {, since the total number of }
$$

children in the town was less than 10,000, correction formula was used to calculate the final sample size and it became 292 with $10 \%$ nonresponse rate. The study subjects were selected using systematic random sampling.

\section{Data collection tool and procedure}

Pre-tested and interviewer administered structured questionnaires and physical examination was used to collect quantitative data. Five registered female nurses and two laboratory technicians were recruited to collect the data. For laboratory examination, before collecting specimens any ointment or local appliances on children's head were removed with alcohol and then infected hairs appearing as broken off hairs were collected with gentle rubbing with moist gauze and transported in a folded square paper to laboratory. The specimens were treated for 30 minutes with two drops of potassium hydroxide $(\mathrm{KOH})$ and carefully examined under low (X10) and high (X40) power objective lens for the presence of hyphae and bud.

Two Bachelor degree holder nurses supervised the overall data collection process and check for filled questionnaire for consistency and completeness. The questionnaire was prepared in English language and translated to Sidamigna language/local language and back to English to maintain the consistence of the data. Training was given to data collectors for two days. During and after data collection, questionnaires were reviewed and checked for completeness and relevance by the principal investigators and the supervisors.

\section{Data processing and analysis}

After data collection, each questionnaire was checked for completeness and code was given before data entry. Data was cleaned and entered into computer by using EPI Info version 3.5.3 and the analysis was done using SPSS version 20.0. Data was edited and cleaned before data analysis.

Frequency, percentage and descriptive summaries were used to describe the study variable using univarite analysis. Logistic regression was carried out to identify factors associated with presence of tinea capitis. Adjusted odd ratio (AOR) with 95\% Confidence Interval (CI) and $\mathrm{p}$-value were computed to measure the associations between the outcome variable and the explanatory variables. A p-value of less than 0.05 was considered as a significant result. The fitness of the model was checked by Hosmer and Lemeshow and the p-value was found to be 0.966 .

\section{Ethical consideration}

Ethical clearance was obtained from the ethical clearance Institutional Review Board of Hawassa University, College of Medicine and Health Sciences. Supportive letters was taken from Dorebafano town health office. The study participants were informed about the purpose of the study and informed written and verbal consent was taken from parents/care takers of children. During data collection children with clinical manifestation of tinea capitis were provided health education and referred the near bye health facilities for further investigation and treatment.

\section{Results}

\section{Socio demographic and economic characteristics}

A total of 288 children aged 6-15 were included in the study with a response rate of $98.6 \%$ where, $166(57.6 \%)$ were females. Age of the study subjects ranged from 6 to 15 years with three among four 217 $(75.3 \%)$ children were found in the age range 6 to 10 years and the mean age of the study participants was 8.96 years $(+2.625)$ standard deviation (SD). The average family size of the study participants was 5.22. Two hundred sixty eight (93.1\%) and 276 (95.8) were protestant by religion and Sidama by ethnicity, respectively (Table 1 ).

Concerning education status, one among five, 58 (20.1\%) mothers attended secondary and above school, 125 (43.4\%) of their partners/ husbands attended primary education and nearly two among three children attended grade 1 to 4 . Almost two among three mothers, 182 (63.2\%) were house wife by occupation and 118 (41\%) of their counterparts were merchant by occupation. One hundred four study participants $(30.4 \%)$ were living in rural areas. 
Citation: Hibstu DT, Kebede DL (2017) Epidemiology of Tinea Capitis and Associated Factors among School Age Children in Hawassa Zuria District, Southern Ethiopia, 2016. J Bacteriol Parasitol 8: 309. doi:10.4172/2155-9597.1000309

Page 3 of 5

The average number of living rooms of the study participant was found to be 2.2 with the minimum and the maximum being 1 and 5 respectively. Almost one in five, 66 (22.9\%) study participants perceived that there is overcrowding in the living household. Nearly two among three households, 169 (58.7\%) had monthly income of one thousand and less Ethiopian Birr (Table 2).

\begin{tabular}{|c|c|c|c|}
\hline \multicolumn{2}{|l|}{ Characteristics } & \multirow{2}{*}{$\begin{array}{l}\text { Frequency } \\
217\end{array}$} & \multirow{2}{*}{$\begin{array}{l}\text { Percentage } \\
75.3\end{array}$} \\
\hline Age of child in years & $6-10$ & & \\
\hline & $11-15$ & 71 & 24.7 \\
\hline \multirow[t]{2}{*}{ Sex } & Male & 122 & 42.4 \\
\hline & Female & 166 & 57.6 \\
\hline \multirow[t]{3}{*}{ Religion } & Protestant & 268 & 93.1 \\
\hline & Orthodox & 4 & 1.4 \\
\hline & Muslim & 16 & 5.6 \\
\hline \multirow[t]{3}{*}{ Ethnicity } & Sidama & 277 & 96.2 \\
\hline & Gurage & 7 & 2.4 \\
\hline & Silte & 4 & 1.4 \\
\hline \multirow[t]{2}{*}{ Family size } & $1-4$ & 103 & 35.8 \\
\hline & $\geq 4$ & 185 & 64.2 \\
\hline \multirow[t]{2}{*}{ Place of residence } & Urban & 221 & 76.7 \\
\hline & Rural & 67 & 23.3 \\
\hline \multirow{4}{*}{$\begin{array}{l}\text { Educational status of } \\
\text { children }\end{array}$} & Didn't start & 41 & 14.2 \\
\hline & Kindrgarten & 47 & 16.3 \\
\hline & $1-4$ & 179 & 62.2 \\
\hline & $>4$ & 2 & 7.3 \\
\hline \multirow[t]{4}{*}{ Maternal education } & $\begin{array}{l}\text { Can't read and } \\
\text { write }\end{array}$ & 76 & 26.4 \\
\hline & Read and write & 31 & 10.8 \\
\hline & Primary education & 123 & 42.7 \\
\hline & $\begin{array}{l}\text { 2nd education } \\
\text { and above }\end{array}$ & 58 & 20.1 \\
\hline \multirow[t]{4}{*}{ Paternal education } & $\begin{array}{l}\text { Can't read and } \\
\text { write }\end{array}$ & 53 & 18.4 \\
\hline & Read and write & 31 & 10.8 \\
\hline & Primary education & 125 & 43.4 \\
\hline & $\begin{array}{l}\text { Secondary and } \\
\text { above }\end{array}$ & 79 & 27.4 \\
\hline \multirow[t]{3}{*}{ Maternal occupation } & Housewife & 182 & 63.2 \\
\hline & Merchant & 39 & 13.5 \\
\hline & $\begin{array}{l}\text { Governmental } \\
\text { employee }\end{array}$ & 67 & 23.3 \\
\hline Paternal occupation & $\begin{array}{l}\text { Governmental } \\
\text { employee }\end{array}$ & 68 & 23.6 \\
\hline
\end{tabular}

\begin{tabular}{|l|l|l|l|}
\hline & Farmer & 102 & 35.4 \\
\cline { 2 - 4 } & Merchant & 118 & 41 \\
\hline Number of living rooms & $\leq 2$ & 196 & 68 \\
\cline { 2 - 4 } & $>2$ & 92 & 31.9 \\
\hline $\begin{array}{l}\text { Monthly Family income } \\
\text { (in Ethiopian Birr) }\end{array}$ & $\leq 1000$ & 169 & 58.7 \\
\cline { 2 - 4 } & $1001-2000$ & 55 & 19.1 \\
\cline { 2 - 4 } & $2001-3000$ & 23 & 8 \\
\cline { 2 - 4 } & $3001-4000$ & 41 & 14.2 \\
\hline
\end{tabular}

Table 1: Socio demographic and socioeconomic characteristics of the study subjects in Hawassa Zuria District, Sidama Zone, Southern Ethiopia, 2016.

\begin{tabular}{|c|c|c|c|}
\hline \multicolumn{2}{|l|}{ Variables } & Frequency & Percentage \\
\hline \multicolumn{4}{|l|}{ Clinical Manifestation: } \\
\hline \multirow[t]{2}{*}{ Itching } & Yes & 97 & 33.7 \\
\hline & No & 191 & 66.3 \\
\hline \multirow[t]{2}{*}{ Loss of hair } & Yes & 30 & 10.4 \\
\hline & No & 258 & 89.6 \\
\hline \multirow[t]{2}{*}{ Scarring alopecia } & Yes & 14 & 4.9 \\
\hline & No & 274 & 95.1 \\
\hline \multirow[t]{2}{*}{ Oozing of the lesion } & Yes & 7 & 2.4 \\
\hline & No & 281 & 97.6 \\
\hline \multirow[t]{2}{*}{ Scaly lesion } & Yes & 121 & 42 \\
\hline & No & 167 & 58 \\
\hline \multirow[t]{2}{*}{ Sharing of bed } & Yes & 206 & 71.5 \\
\hline & No & 82 & 28.5 \\
\hline \multirow[t]{2}{*}{ Sharing of blades/scissors for cutting hair } & Yes & 61 & 21.2 \\
\hline & No & 227 & 78.8 \\
\hline \multirow[t]{2}{*}{ History of contact with animals } & Yes & 166 & 57.6 \\
\hline & No & 122 & 42.4 \\
\hline \multirow{2}{*}{$\begin{array}{l}\text { Presence tinea capitis in the family } \\
\text { member }\end{array}$} & Yes & 47 & 16.3 \\
\hline & No & 241 & 83.7 \\
\hline
\end{tabular}

Table 2: Tinea capitis related characteristics among children/study subjects in Hawassa Zuria District, Sidama Zone, Southern Ethiopia, 2016.

Of the study subjects $97(33.7 \%)$ and $30(10.4 \%)$ had a clinical manifestation of itching and loss of hair in their head.

Nearly seven among ten, 206 (71.5\%) study subjects shared sleeping bed with siblings and parents. It was found that $166(57.6 \%)$ of the household members had history of contact with animals. It was also 
Page 4 of 5

observed that forty seven (16.3\%) of the study subjects family members ah history of tinea capitis related illness (Table 2).

\section{Magnitude of Tinea capitis}

The overall magnitude of tinea capitis among the study subjects was 93 (32.3\%) [CI: $27.3 \%-37.5 \%]$.

Among the total positive results of tinea capititis microscopically nearly two in three $72 / 93$ (77.41\%), three in ten $28 / 93(30.10 \%)$ and $13 / 93$ (13.97\%) children had a clinical manifestation of itching, loss of hair and scaring alopecia, respectively (Table 2).

\section{Associated factors with occurrence of Tinea Capitis}

In the multiple binary logistic regression analysis after controlling potential confounders: age of child, sex of child, educational status of the child, sharing of bed, presence of similar illness in the family members were found to be significantly associated with occurrence of tinea capitis among children.

The present study revealed that children in the age group 6-10 years old were three times $(\mathrm{AOR}=3.2,95 \% \mathrm{CI}:(1.4,7.0))$ more likely to develop tinea capitis compared with the age group 11-15 years old.

\begin{tabular}{|c|c|c|c|c|c|}
\hline \multirow{2}{*}{\begin{tabular}{l|} 
Variables \\
$\begin{array}{l}\text { Age of } \\
\text { child }\end{array}$
\end{tabular}} & \multicolumn{2}{|c|}{$\begin{array}{l}\text { Presence of } \\
\text { tinea capitis }\end{array}$} & \multirow[t]{2}{*}{$\begin{array}{l}\text { Crude Odd Ratio } \\
\text { (COR) }\end{array}$} & \multirow[t]{2}{*}{$\begin{array}{l}\text { Adjusted Odd } \\
\text { Ratio (AOR) }\end{array}$} & \multirow[t]{2}{*}{$\begin{array}{l}\mathrm{P} \text { - } \\
\text { value }\end{array}$} \\
\hline & Yes & No & & & \\
\hline $6-10$ & 78 & 119 & $2.10(1.10,3.90)$ & $3.20(1.40,7.00)$ & 0.005 \\
\hline $11-15$ & 17 & 56 & 1 & 1 & \\
\hline \multicolumn{6}{|l|}{ Sex } \\
\hline Male & 48 & 74 & 1 & 1 & \\
\hline Female & 45 & 121 & $1.70(1.06,2.90)$ & $0.10(0.03,0.40)$ & 0.001 \\
\hline \multicolumn{6}{|c|}{ Educational status of the child } \\
\hline Didn't start & 12 & 29 & $1.34(0.47,3.86)$ & $1.66(0.40,6.89)$ & 0.485 \\
\hline $\begin{array}{l}\text { Kindergarte } \\
\mathrm{n}\end{array}$ & 23 & 24 & $3.07(0.97,9.74)$ & $6.94(1.43,33.53)$ & 0.016 \\
\hline $1-4$ & 53 & 126 & $1.32(0.40,4.44)$ & $2.65(0.51,3.13)$ & 0.245 \\
\hline$\geq 5$ & 5 & 16 & 1 & 1 & \\
\hline \multicolumn{6}{|c|}{ Similar illness in the family } \\
\hline Yes & 40 & 7 & $15.95(6.74,37.79)$ & $6.50(2.42,17.44)$ & 0.00 \\
\hline No & 53 & 188 & 1 & 1 & \\
\hline
\end{tabular}

Table 3: Factors Associated tinea capitis among children in Hawassa Zuria District, Sidama Zone, Southern Ethiopia, 2016.

The study showed that the occurrence of tinea capitis among females was $90 \%$ (AOR $=0.10$, CI $(0.03,0.40)$ less likely to occur compared with males.

Children whose school level in kindergarten were 7 times (AOR=6.9, 95\% CI: 1.4, 33.5) more likely to develop tinea capitis than who were above grade 5 and above.
Another important factor was having tinea capitis among the family members. The probability of tinea capitis occurrence was 6 $(\mathrm{AOR}=6.496,95 \%$ CI: 2.42, 17.43) times higher among children whose family members had tinea capitis (Table 3 ).

\section{Discussion}

In spite of the high cases being detected in poor resource settings, tinea capitis has a worldwide distribution with most cases being diagnosed in Africa, Asia, and Southern and Eastern Europe. Thus, this study had tried to determine the magnitude of tinea capitis and associated factors among school age children in Dore Bafano town, Hawassa Zuria District, Sidama Zone, Southern Ethiopia

In the present study the magnitude of tinea capitis was determined to be $32 \%$ [CI: $27.3 \%-37.5 \%$ ] supported with laboratory investigation. This prevalence was indicated to be lower than those obtained in North West Ethiopia (47.5\%), [11]. Tulugudu Island, Ethiopia, (79.5\%) $[23,24]$, in Mathare, an informal settlement in Nairobi, Kenya (81.2\%) [25], nearly similar with a study conducted in Kenya (33.3\%) [10], and higher than a study done in Tanzania (4\%) [25]. Many factors has been contributing for the difference in the magnitude of tinea capitis which might be due to population growth, close contact among infected children at home and school, and poor personal hygiene as a result of less access to water and hygienic materials in general.

This study demonstrated that tinea capitis is more likely to increase among school aged children who were in the age group 6-10 years compared with children in the age group 11-15 years old. This result was supported with the finding s in Nigeria [10] and Kenya [24]. This might be due to as a result of poor hygiene at this age as well as the absence of saturated fatty acids that provide a natural protective mechanism against dermatophytoses.

On the other hand, probably because females are more cognizant of their appearances; and as a result they care more about personal hygiene and hair that promotes health than males, it was pointed out tinea capitis was more likely to occur among males in comparison with females whose number of children were above four. It is also perhaps that males were most infected with high rates probably due to with haircuts, unclean barbers and personal equipments (like combs) with friends frequently compared with females. This study was in agreement with the finding in Western Nigeria [26,27].

Tinea capitis was more likely to occur among children who were attending kindergarten compared with children attending grade five and above. This might be explained by the fact that there is no question that as level of education increase, awareness and knowledge of students about personal hygiene will be increased and they will be able to care themselves. Education provides better health knowledge and improves the effectiveness of health behavior.

The study also revealed that the probability of having tinea capitis was increased among children whose family members had similar illness (tinea capitis) compared with those who were free from tinea capitis. The higher tinea capitis among children whose family members had similar illness might be due to the fact that there would be a higher probability of frequent contact and sharing of personal equipment such as combs and towels with the infected individuals.

When interpreting the finding of this study, scholars need to take into consideration the following limitation. First, the cross sectional nature of the data had made impossible to arrive at the causal relation between the different explanatory variables and occurrence of tinea 
Citation: Hibstu DT, Kebede DL (2017) Epidemiology of Tinea Capitis and Associated Factors among School Age Children in Hawassa Zuria

Page 5 of 5

capitis. Second, culture was not performed to identify the types of fungal species.

\section{Conclusion}

In general the magnitude of tinea capitis among the study subjects was found to be $32 \%$ [32\%, CI: $27.3 \%-37.5 \%]$. Age, sex and educational status of children and presence of similar illness were identified to be independent factors for occurrence of tinea capitis.

Health promotion and health education measures needs to be given emphasis to promote good hygiene, better living conditions, early identification and treatment and there needs to have a continuous epidemiological surveillance of tinea capitis in a community as an important component in the prevention and control of this infectious disease.

\section{Acknowledgement}

Hawassa University, College of Medicine and Health Sciences should be acknowledged for supporting financially to carry out this research.

\section{Contributions}

Desalegn Tsegaw Hibstu (DTH) took part in planning the study, monitoring data collection process and analyzing the data, writing the result and the manuscript. Deresse Legesse Kebede (DLK) participated in data collection process and writing the manuscript. Both authors read and approved the final manuscript.

\section{Competing Interest}

The authors declared that there are no competing interests

\section{References}

1. Seebacher C, Bouchara JP, Mignon B (2008) Updates on the epidemiology of dermatophyte infections. Mycopathologia 166: 335-352.

2. Silverberg NB, Weinberg JM, DeLeo VA (2002) Tinea capitis: Focus on African American women. J Am Acad Dermatol 46: 120-124.

3. Abdel-Rahman SM, Herron J, Fallon-Friedlander S, Hauffe S, Horowitz A, et al. (2005) Pharmacokinetics of terbinafine in young children treated for Tinea capitis. Pediatr Infect Dis J 24: 886-891.

4. Menan, Higgins, Elewski (2002) Common Skin Diseases. 17th Edn PP:19.

5. Oguzkaya Artan M, Koc AN, Baykan Z, Buldu H (2013) Prevalence of Tinea capitis in primary school children. Int J Med Investig 1: 104-110

6. Yu J, Li R, Bulmer G (2005) Current topics of tinea capitis in China. Nihon Ishinkin Gakkai Zasshi 46: 61-66.

7. Yehia MA, El-Ammawi TS, Al-Mazidi KM, Abu El-Ela MA, Al-Ajmi HS (2010) The Spectrum of fungal infections with a special reference to dermatophytoses in the capital area of Kuwait during 2000-2005: a retrospective analysis. Mycopathologia 169: 241-246.
8. Feuilhade M, Lacroix C (2001) Epidemiology of tinea capitis. Presse Med 30: 499-504.

9. Hainer BL (2003) Dermatophyte infections. Am Fam Physicians 67: 101-108.

10. Chepchirchir A, Bii C, Ndinya-achola JO (2009) Dermatophyte infections in primary school children in Kibera slums of Nairobi. Int J Dermatol 24: 116-119.

11. Ali J, Woldeamanuel Y, Yifru S (2009) Prevalence of tinea capitis and the causative agent among school children in Gondar, North West Ethiopia. Ethiop Med J 47: 261-269.

12. Shehu MM, Bilyaminu R (2014) Incidence of Tinea capitis among school age children in Runjin Sambo Area Of Sokoto State-Nigeria. Journal of Zoological and Bioscience 3: 37-42.

13. Ali-Shtayeh MS, Salameh AA, Abu-Ghdeib SI, Jamous RM, Khraim H (2002) Prevalence of Tinea Capitis as well as of Symptomatic Carriers in School children in Nablus area (Palestine). Mycoses 45: 188-194.

14. Richardson M, ElewskiB (2000) Superficial Fundal Infections. 9th Edn. PP: 62-66.

15. Rebollo N, Lopez-Barcenas AP, Arenas R (2008) Tinea capitis. Departmento de dermatologia 99: 91-100.

16. Arenas R (2002) Dermatofitosis en México. Revista Iberoamericana de Micologia 19: 63-67.

17. Asticcioli S, Di Silverio A, Sacco L, Fusi I, Vincenti L, et al. (2008) Dermatophyte infections in patients attending a tertiary care hospital in northern Italy. New Microbiol 31: 543-548.

18. Guerrant RL, Walker DH, Weller PF (2011) Tropical Infectious Diseases 3rd edn: Principles, Pathogens and Practice. Elsevier Churchill, Livingstone, Philadelphia, USA.

19. Sheikh HA (2009) Epidemiology of dermatophytes in the Eastern Province of Saudi Arabia, Res J of Microb 4: 229-234.

20. Ayanlowo O, Akinkugbe A, Olandle R, Balogun M (2014) Prevalence of Tinea capitis infection among primary school children in a rural setting in south west Nigeria. J Public Health Africa 5: 349.

21. Kundu D, Mandal L, Sen G (2012) Prevalence of Tinea capitis in school going children in Kolkata, West Bengal. 3: 152-155.

22. Sidat MM, Correia D, Buene TP (2007) Tinea capitis among children at one suburban primary school in the city of Maputo,Mozambique. Rev Soc Bras Med Trop 40: 473-475.

23. Woldeamanuel Y, Mengistu Y, Chryssanthou E, Petrini B (2005) Dermatophytosis in Tulugudu Island, Ethiopia, Med Mycol 43: 79-82.

24. Moto JN, Maingi JM, Nyamache AK (2015) Prevalence of Tinea capitis in school going children from Mathare, informal settlement in Nairobi, Kenya. BMC Research Notes 8: 274.

25. WHO (2005) Epidemiology and management of common skin diseases in children in developing countries. WHO/FCH/CAH/05.12.

26. Oyedeji OA, Okeniyi JA, Ogunlesi TA, Onayemi O, Oyedeji GA, et al. (2006) Parental Factors Influencing the Prevalence of Skin Infections and Infestations among Nigerian Primary School Pupils. The Internet J of Dermat 3: 1531-3018.

27. Amoran OE, Runsewe-Abiodun OO, Mautin AO, Amoran IO (2011) Determinants of dermatological disorders among school children in Sagamu, Nigeria. Educational Research 2: 1743-1748. 